\title{
Vitamin $\mathbf{A}$ and carotenoid status in rural China
}

\author{
BY GUANGYA WANG', THIERRY A. BRUN ${ }^{2}$, CATHERINE A. GEISSLER ${ }^{3}$, \\ BANOO PARPIA*, MARTIN ROOT*4, MING LI*, T. COLIN CAMPBELL,* \\ AND JUNSHI CHEN' \\ ${ }^{1}$ Institute of Nutrition and Food Hygiene, Chinese Academy of Preventive Medicine, Beijing, China \\ ${ }^{2}$ The World Bank, Washington, DC, USA \\ ${ }^{3}$ Department of Nutrition and Dietetics, Division of Health Sciences, Kings College, University of \\ London, W8 7 AH \\ ${ }^{4}$ Division of Nutritional Sciences, Savage Hall, Cornell University, Ithaca, NY 14853, USA
}

(Received 18 September 1995 - Revised 15 April 1996-Accepted 1 May 1996)

\begin{abstract}
Vitamin A status of 260 groups of twenty-five males or twenty-five females, aged 35-64 years, surveyed in twenty-four provinces of the People's Republic of China, was assessed by measuring plasma retinol, retinol-binding protein and $\beta$-carotene concentrations. Direct measurements of food intake over a $3 \mathrm{~d}$ period and questionnaire data on the frequency of consumption of vegetables, fruits, animal products and other dietary items were also used. Vitamin A status appeared to be low only in specific counties but in general was satisfactory or only marginally deficient. Plasma $\beta$-carotene levels were strikingly low in comparison with Western levels despite generous vegetable consumption suggesting that intake of vitamin A precursors may have been adequate but not abundant enough to maintain high circulating plasma levels of $\beta$-carotene. Plasma $\beta$-carotene, for both males and females, was significantly correlated with the frequency of consumption of green vegetables. Plasma retinol, for males, was highly correlated with meat, fish, oil and alcohol consumption expressed both in quantity or frequency of consumption. Higher levels of plasma retinol, together with lower levels of plasma $\beta$-carotene in males compared with females, suggest that men consume more animal products or may have higher retinol requirements and therefore a higher rate of conversion of $\beta$-carotene to retinol.
\end{abstract}

Vitamin A: Retinol: $\beta$-Carotene: Retinol-binding protein: Vegetable consumption

The low vitamin A status of some segments of the Chinese population has been a concern for health authorities since the early 1950s (Freedman, 1978) and although considerable improvements in public health and nutrition have occurred over the last 40 years there is evidence suggesting that vitamin A status may be marginal in certain areas and population groups.

A number of studies have reported low blood or intake levels of retinol and/or $\beta$ carotene in China (Freedman, 1978; Solomons \& Russell, 1980; Thurnham et al. 1982; Chen, 1986; Cui, 1987; Tian et al. 1988; Zhao, 1988; Wang et al. 1989 a; Campbell et al. 1990; Chen et al. 1990; Lie et al. 1993). Vitamin A intakes were low in kindergarten, primary school and middle school children (mean 51, 68 and $45 \%$ respectively of the Chinese recommended daily allowances, RDA) in the 1982 nationwide nutrition survey (Chen, 1986), in children under 3 years of age in northern Hebei Province (Lie et al. 1993), and in preschool children and lactating mothers in Beijing and its suburbs (Cui, 1987). Plasma retinol levels were found to be low in Linxian where $20-35 \%$ of the population had

* For reprints. 
levels below $0.70 \mu \mathrm{mol} / \mathrm{l}(20 \mu \mathrm{g} / \mathrm{dl})$ possibly contributing to the high prevalence of oesophageal cancer (Yang et al. 1984), in $40 \%$ of Tianjin infants and preschool children, particularly in 6-12-month-old infants (Tian et al. 1988), and in Hebei children under 3 years of age (Lie et al. 1993), but adequate in staff members of the Institute of Nutrition and Food Hygiene in Beijing in both summer and winter (Zhao, 1988). Plasma $\beta$-carotene levels have also been found to be low in a significant proportion of the population, for example in Zhengzhou University students (Cui, 1987) and Henan farmers (Thurnham et al. 1988).

It is not clear, however, whether the prevalence of the deficient vitamin A status is the result of a supply shortage, a demand problem, and/or a food behavioural problem. Of the numerous factors that can, potentially, influence vitamin A status, the ones most often implicated are food beliefs, unfavourable interactions with other nutrients, infectious diseases, and chronic parasitic infestation. Dietary constituents which may compromise vitamin A status include insufficient intake of fat, which facilitates intestinal absorption of the vitamin, and possibly insufficient intake of protein (Underwood, 1984). Mean dietary fat intake in rural China in 1983 was only $15 \%$ of energy (Chen et al. 1990) and could be a limiting factor for the absorption of retinol and carotenoids among Chinese children, as evidenced in other parts of the world (Gopalan et al. 1960; Solon et al. 1978; Latham \& Solon, 1986). Zn deficiency, also, has been reported to reduce the synthesis of retinolbinding protein (RBP) and to decrease plasma retinol levels (Solomons \& Russell, 1980). Intestinal parasites, also, are known to affect vitamin A status and growth. Ascariasis and giardiasis have been shown to impair vitamin A absorption (Katsampes et al. 1944; Farthing et al. 1986).

An analysis of the vitamin A status of a sample population of adults in sixty-five mostly rural counties in China was undertaken as part of a larger investigation of the relationship between various cancer mortality rates and dietary and lifestyle factors (Chen et al. 1990). The field survey work was conducted between September and November 1983, on 6500 subjects aged 35-64 years, in which a comprehensive set of biochemical, nutritional and lifestyle indicators were measured and recorded. This report summarizes those variables which are generally known to be closely related to the assessment of vitamin A nutritional status.

\section{METHODS}

The methods and procedures used in this study are described in detail in the study monograph by Chen et al. (1990) and a summary of the principal parts of the methodology, including sampling procedures and analytical methods, are included in an earlier manuscript concerning riboflavin status (Campbell et al. 1990). Briefly, sixty-five mostly rural counties were selected to represent the full range of mortality rates for seven of the most prevalent cancers in China, and within each county two communes were randomly selected to give a total of 130 survey sites. Comprehensive information on dietary intakes, blood, urine and food constituents, as well as questionnaire data on frequency of food intake and other lifestyle characteristics, was collected from fifty randomly selected adults (twenty-five males and twenty-five females) aged 35-64 years at each survey site. Methods for other nutrient exposures not reported in the earlier publication (Campbell et al. 1990) are summarized below.

\section{Blood collection}

Blood samples were obtained from approximately 6500 individuals. Fasting intravenous blood $(10 \mathrm{ml})$ was drawn (before a riboflavin and vitamin C 'load' test) from each subject between 06.00 hours and 12.00 hours, using trace-mineral-free heparinized Vacutainers 
(Becton-Dickinson Inc., Rutherford, NH, USA). Samples were immediately placed on ice in light-free Thermos -type jars and then transported to the county laboratory (within $4 \mathrm{~h}$ of the last blood sample). On arrival at the county laboratory the blood samples were immediately divided into fractions and stored at $-15^{\circ}$ to $-20^{\circ}$. Within 2 months all fractions were shipped by air in insulated transporter boxes on dry ice to the Institute of Nutrition and Food Hygiene at the Chinese Academy of Preventive Medicine in Beijing. Samples were then thawed and equal aliquots of each individual sample were combined into 260 sex- and commune-specific pools. All samples were then stored at $-30^{\circ}$ and analysed for retinol, carotenes and other variables in early 1984.

\section{Biochemical analyses}

Plasma levels of $\alpha$ - and $\beta$-carotene were determined by the HPLC method of Wang $e t$ al. $(1989 b)$. Plasma levels of retinol were determined by a HPLC method using a modification of the procedures of Driskell et al. (1982) and DeRuyter \& Leenheer (1978) as described by Chen et al. (1990). This method allowed simultaneous measurement of $\alpha$ - and $\gamma$ tocopherol. Plasma RBP, an $\alpha_{1}$-globulin, was determined by a kit procedure utilizing radial immunodiffusion plates (LC-Partigen ${ }^{\otimes}$ ) obtained from Calbiochem-Behring, La Jolla, CA, USA. The assay is based on principles outlined by Mancini et al. (1965). Plasma RBP, complexed with prealbumin in a molar ratio of $1: 1$, binds and transports retinol (Kanai et al. 1968). Internal standards were used for the analyses of plasma carotenoids and vitamins $A$ and E. Duplicate analyses were performed on the HPLC. The CV for the analyses were $4 \%$ for retinol, $10 \%$ for $\gamma$-tocopherol, $5 \%$ for $\alpha$-tocopherol and $10 \%$ for $\beta$ - and for $\alpha$ carotene. Pooled plasma was used as a quality control sample and analysed as an additional sample each day.

\section{Dietary survey and questionnaire}

Food consumption was measured over three successive days in thirty households (fifteen households in each of two production teams in one of the two communes) in each of the sixty-five counties. A combination of food weighing and food disappearance techniques was used to estimate household consumption. Food intakes were adjusted for age, sex and physical activity to yield standardized estimates per 'reference man', defined as an adult male, 19-59 years of age, $65 \mathrm{~kg}$ body weight, undertaking very light physical work (Chen et al. 1990). Average daily nutrient intakes were calculated on the basis of Chinese food composition tables (Institute of Health, 1980) and expressed per reference man.

A questionnaire on food consumption frequency, alcohol intake, smoking, health status and reproductive history was given to all subjects who donated blood, so these data were available by sex. In addition to frequency of intake of seventeen foods, data on the yearly ration of grains (rice, wheat, maize, millet and sorghum), legumes, sweet potatoes and cooking oil were also obtained from each survey subject (Chen et al. 1990).

\section{Statistical analysis}

All assays reported in this manuscript were conducted on pooled plasma samples primarily because the major objective of the original study design was to assess the relationship between nutritional factors and county-level mortality rates by disease and sex. Thus, for the purposes of the original ecological study, only average values of a comprehensive set of biochemical markers of nutritional status and of dietary intakes were relevant and these were successfully obtained by analyses of pooled plasma samples. The validity of using pooled samples to obtain average values was tested for several samples including the assays 
for plasma cholesterol and retinol, and the results indicate excellent agreement between pool values and averages of individual values (Chen et al. 1990). Information on the variability of the distribution of these various biochemical indicators, relevant for the purposes of this manuscript however, was not available due to the pooling procedure used. One county (Tuoli County in Xinjiang Autonomous Region), composed primarily of an ethnic minority population of herdspeople, had disproportionately high values for retinol, lipid and protein intake due to an exceptionally high intake of animal foods. This 'outlier' was not included in the analysis, to characterize more accurately the average intakes of the rural Chinese population and to avoid the undue influence of one data point on the results.

Descriptive statistics including means, medians, standard deviations and ranges of average county values were computed by sex for all relevant biochemical indicators of vitamin A status, dietary intakes of nutrients and foods and frequencies of intake of selected foods. Pearson product-moment correlation coefficients were used to examine the linear relationships between biochemical indicators of vitamin A status and selected plasma and dietary factors. These correlation coefficients are measures of the degree of association between two factors at the county level. They do not establish causality and may not be supported at the level of the individual. All probability levels of significance reported are two-sided and all the data were analysed using the SAS statistical software package (Statistical Analysis Systems, 1985).

\section{RESULTS}

Means and ranges of average county levels of plasma retinol, $\alpha$ - and $\beta$-carotene and RBP for both sexes contrasted with values for Western subjects are shown in Table 1. Mean plasma retinol was significantly higher for males $(1.78 \mu \mathrm{mol} / \mathrm{l})$ than for females $(1.43 \mu \mathrm{mol} / \mathrm{l})$ although the range of county means for plasma retinol was similar to that for Western individuals. Male values for plasma RBP $(1.48 \mu \mathrm{mol} / \mathrm{l})$ were significantly higher than female values $(1.33 \mu \mathrm{mol} / \mathrm{l})$ while values for both sexes were lower than the minimum value of the Western range $(1.90 \mu \mathrm{mol} / 1)$. In fact, RBP levels in this population were much lower relative to Western values than for retinol. $\beta$-Carotene values were significantly lower for males than for females within China. Plasma $\beta$-carotene levels were also lower than Western values, despite a diet based primarily on plant foods.

Mean dietary intakes of retinol and carotenoids obtained from food sources are presented in Table 2 . Average daily retinol intake (28 retinol equivalents (RE)) was far below Western intake (990 RE) while mean carotenoid intake in China (238 RE), which varied widely, was almost double Western intakes (143 RE). The intakes of energy, fat and protein are also shown because of their possible relevance to overall vitamin status. Although energy intakes, corrected for body weight, were higher in China than in the US, lipid intakes for these mostly rural Chinese (14.5\% energy) were far below Western intakes (about 36-40\% energy). Total protein intake (64 g), also, was considerably below Western intake $(91 \mathrm{~g})$, but the most remarkable difference was the proportion of protein from animal foods, being $11 \%$ (including fish) in China and $70 \%$ in the US (United States Department of Agriculture, 1984).

Table 3 shows the daily intake of vitamin A-containing foods in China expressed 'per reference man', calculated from $3 \mathrm{~d}$ household dietary intakes. The consumption of vegetables in China was higher than in the US. Although diet comparisons are difficult, it appears that total vegetable consumption was about twice as high in China as in the US. In contrast, the intake of retinoid-containing foods was much lower: Chinese males consumed, on average, one tenth of the meat and eggs and one hundredth of the milk and 
Table 1. Plasma indicators of vitamin A status of mostly rural populations in sixty-five Chinese counties*

(Values are means of county means and standard deviations of the distribution of county means together with ranges; median values are given in parentheses)

\begin{tabular}{|c|c|c|c|c|c|c|}
\hline \multirow[b]{3}{*}{$\begin{array}{l}\text { Retinol } \\
(\mu \mathrm{mol} / \mathrm{l})\end{array}$} & \multicolumn{2}{|c|}{ Male } & \multicolumn{2}{|c|}{ Female } & \multirow{2}{*}{$\begin{array}{c}\text { Statistical } \\
\text { significance of } \\
\text { sex difference } \dagger\end{array}$} & \multirow{2}{*}{$\begin{array}{c}\text { Ranges for } \\
\text { individual Western } \\
\text { subjects } \$\end{array}$} \\
\hline & $\begin{array}{r}\text { Mean SD } \\
\text { (Median) }\end{array}$ & Range & $\underset{\text { (Median) }}{\text { Mean SD }}$ & Range & & \\
\hline & $\begin{array}{c}1.78 \quad 0.35 \\
(1.80)\end{array}$ & $1 \cdot 16-2 \cdot 70$ & $\begin{array}{c}1.43 \quad 0.26 \\
(1.44)\end{array}$ & $0.92-2.09$ & $P<0.001$ & $1.05-2.27 \S$ \\
\hline $\begin{array}{c}\alpha \text {-Carotene } \\
(\mu \mathrm{mol} / \mathrm{l})\end{array}$ & $\begin{array}{c}0.0150 .030 \\
(0.0)\end{array}$ & $0.00-0.18$ & 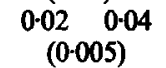 & $0.00-0.23$ & NS & $0.00-0.21^{\prime \prime}$ \\
\hline $\begin{array}{c}\beta \text {-carotene } \\
(\mu \mathrm{mol} / \mathrm{l})\end{array}$ & $\begin{array}{c}0.17 \quad 0.09 \\
(0.15)\end{array}$ & $0.05-0.53$ & $\begin{array}{c}0.22 \quad 0.10 \\
(0-20)\end{array}$ & $0.07-0.48$ & $P<0.001$ & $0.05-1 \cdot 29$ \\
\hline $\begin{array}{l}\mathrm{RBP} \\
(\mu \mathrm{mol} / \mathrm{l})\end{array}$ & $\begin{array}{c}1.48 \quad 0.24 \\
(1.48)\end{array}$ & $1.00-2.05$ & $\begin{array}{c}1.330 .24 \\
(1.31)\end{array}$ & $0.81-1.00$ & $P<0.001$ & $1.90-2 \cdot 40^{\prime \prime}$ \\
\hline
\end{tabular}

RBP, retinol-binding protein.

* For details of procedures, see pp. 810-811.

† A two-tailed $t$ test was used to assess the statistical significance of the difference between values for males and females.

$\ddagger$ Ranges for Western subjects are for individual males.

From Tietz (1986).

"From Staczwicz-Sapuntzakis et al. (1987).

Table 2. Dietary intake of retinol, total carotenoids and selected macronutrients obtained in a $3 d$ household dietary survey in sixty-five rural Chinese counties*

(Values are means of county means and standard deviations of the distribution of county means, together with ranges. Median values are given in parentheses)

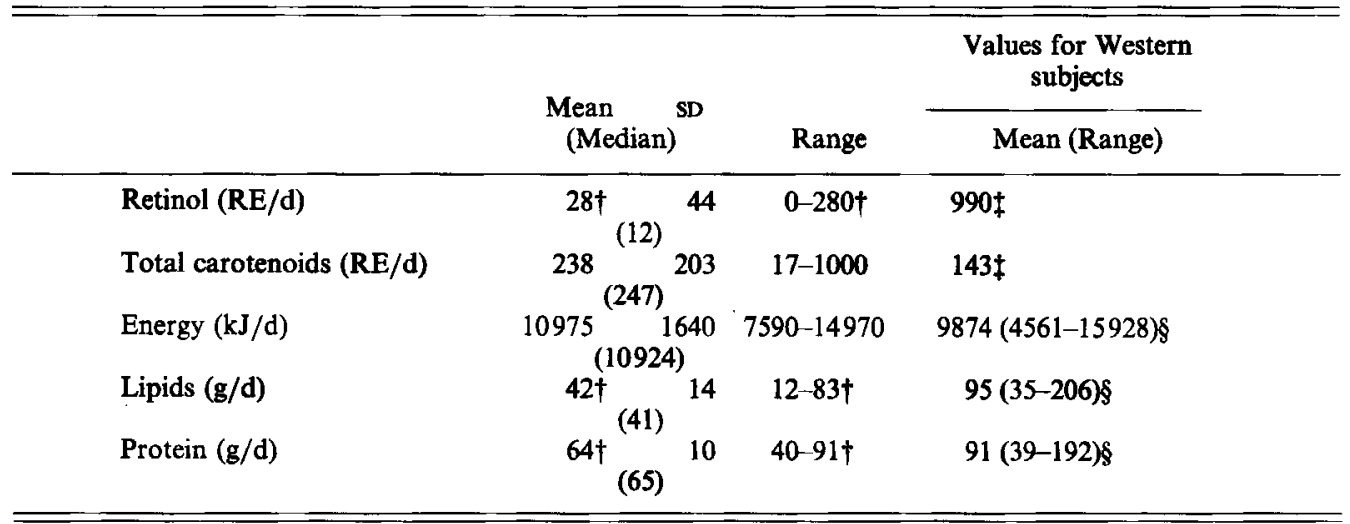

$\mathrm{RE}$, retinol equivalents (1 RE $=6 \mu \mathrm{g}$ total carotene; Ershow \& Wong-Chen, 1990).

* All values expressed per 'reference' male, 19-59 years of age, $65 \mathrm{~kg}$ body weight, and undertaking very light physical work (Chen et al. 1990).

$\dagger$ Excluding Tuoli County in Xinjiang Autonomous Region, where animal food intake was exceptionally high. Values of $1553 \mathrm{RE} / \mathrm{d}, 186 \mathrm{~g}$ lipids/d and $173 \mathrm{~g}$ protein/d were observed.

\$ Mean intake of US males, 19-50 years of age (United States Department of Agriculture, 1986).

$\S$ Range is 5th-95th percentile for US males, 18 -64 years of age (Department of Health and Human Services, 1983). 
Table 3. Dietary intake of vitamin A-containing foods in sixty-five rural Chinese counties* (Values are means of county means and standard deviations, together with ranges. Median values are given in parentheses)

\begin{tabular}{|c|c|c|c|c|}
\hline & $\begin{array}{l}\text { Mean } \\
\quad \text { Medi }\end{array}$ & $\begin{array}{l}\text { SD } \\
\text { ian) }\end{array}$ & Range & US values ${ }^{\dagger}$ \\
\hline Light-coloured vegetables & 211 & 132 & $11-617$ & NA $\ddagger$ \\
\hline Green vegetables & 106 & 114 & $1-691$ & 10 \\
\hline Sea vegetables & 2 (2) & 5 & $0-35$ & NA \\
\hline Preserved vegetables $\S$ & 24 (15) & 44 & $0-314$ & NA \\
\hline Fruits & 18 & 59 & $0-344$ & $147^{\|}$ \\
\hline Milk and dairy products** & $\begin{array}{c}0 \cdot 32 \\
(0)\end{array}$ & $2 \cdot 41$ & $0-19 \cdot 1$ & 287 \\
\hline Eggs & 3 (2) & 4 & $0-15$ & 28 \\
\hline Meat $\dagger$ & (19) & 21 & $0-95$ & 24288 \\
\hline Fish & (7) & 28 & $0-119$ & 21 \\
\hline
\end{tabular}

NA, not available.

* Original data are means of two communes in each county. All Chinese values are expressed per reference man, i.e. male, 19-59 years of age, $65 \mathrm{~kg}$ body weight and undertaking very light physical work (Chen et al. 1990).

+ Values are from United States Department of Agriculture (1986).

$\ddagger$ Vegetable consumption patterns are not easily compared between China and the US. Total vegetable consumption in the US was $272 \mathrm{~g} / \mathrm{d}$. Of this $91 \mathrm{~g} / \mathrm{d}$ was potatoes, $10 \mathrm{~g} / \mathrm{d}$ was dark-green vegetables, $5 \mathrm{~g} / \mathrm{d}$ was deep-yellow vegetables, $46 \mathrm{~g} / \mathrm{d}$ was tomatoes and $121 \mathrm{~g} / \mathrm{d}$ was other vegetables.

\$ Includes both salt-preserved and dried vegetables.

"Raw, dried or canned/cooked fruits and juices. Mean intake was $81 \mathrm{~g}$ excluding juices.

** Excluding two counties with ethnic minority populations of herdspeople, i.e. Tuoli and Xianghuangqi counties in Xinjiang and Neimongol Autonomous Regions respectively, where values of 856 and $147 \mathrm{~g} / \mathrm{d}$ were recorded. Subjects in most counties rarely or never consumed milk or dairy products. (Of the six other counties in which milk and dairy products were consumed, consumption in four counties was $0.1 \mathrm{~g} / \mathrm{d}$, and it was 0.9 and $19 \cdot 1 \mathrm{~g} / \mathrm{d}$ in the other two counties.)

i† Excluding Tuoli county in Xinjiang Autonomous Region where meat intake was $121 \mathrm{~g} / \mathrm{d}$.

$\S \S$ Includes $27 \mathrm{~g}$ of sausages and luncheon meat and $110 \mathrm{~g}$ of meat contained in mixtures.

dairy products of their US comparable age and sex groups. Fish, meat and eggs were consumed more frequently by males than by females in China (Table 4).

Table 5 lists the significant plasma and dietary correlates of plasma retinol and $\beta$ carotene by sex. In general the observed associations were more significant for males than for females and plasma retinol was associated with more factors than plasma $\beta$-carotene. Plasma retinol and plasma $\beta$-carotene were significantly positively correlated. Plasma retinol was significantly correlated with plasma RBP, $\alpha$-tocopherol, and indicators of lipid status. In men only, plasma retinol was positively associated with the intakes of meat (as shown in Fig. 1), alcohol and oil, and negatively associated with the intakes of cellulose and neutral-detergent fibre. In contrast, plasma $\beta$-carotene was positively associated with plasma vitamin $C$ levels and with intake of green vegetables (both sexes) (as shown in Fig. 2 for males), sweet potatoes (females only), and negatively with intakes of plant protein. Any correlations mentioned in the discussion that are not included in the tables shown here are tabulated in the original monograph (Chen et al. 1990). 
Table 4. Frequency of consumption (times per year) of selected vitamin A-containing foods in sixty-five rural Chinese counties*

(Mean values, standard deviations, median values and ranges)

\begin{tabular}{|c|c|c|c|c|c|c|c|c|}
\hline & \multicolumn{4}{|c|}{ Males } & \multicolumn{4}{|c|}{ Females } \\
\hline & Mean & $\mathrm{SD}$ & Median & Range & Mean & SD & Median & Range \\
\hline Salt-preserved vegetables & 136 & 94 & 113 & $3-342$ & 137 & 97 & 116 & $6-338$ \\
\hline Green vegetables & 200 & 88 & 199 & $22-331$ & 199 & 95 & 194 & $26-335$ \\
\hline Carrots & 14 & 28 & 5 & $0-142$ & 14 & 27 & 4 & $0-139$ \\
\hline Potatoes & 43 & 78 & 12 & $0-320$ & 46 & 80 & 11 & $0-326$ \\
\hline Sweet potatoes & 40 & 42 & 29 & $0-170$ & 40 & 41 & 25 & $0-175$ \\
\hline Fruit & 18 & 17 & 12 & $0-109$ & 16 & 17 & 12 & $0-108$ \\
\hline Fish & 43 & 69 & 18 & $0-311$ & 37 & 65 & 12 & $0-276$ \\
\hline Meat & 73 & 57 & 62 & $2-302$ & 53 & 56 & 36 & $1-295$ \\
\hline Egg & 42 & 32 & 34 & $0-122$ & 32 & 28 & 26 & $1-121$ \\
\hline Milk $\uparrow$ & 2 & 7 & 0 & $0-35$ & 2 & 6 & 0 & $0-30$ \\
\hline
\end{tabular}

* Average frequency for county estimated from questionnaire administered to survey subjects. All data rounded to nearest whole number. Data presented exclude Tuoli County in Xingjiang Autonomous Region.

$\dagger$ Excluding two of the sixty-five counties with ethnic minority populations of herdspeople, i.e. Tuoli and Xianghaung'qi counties in the Xinjiang and Neimongol Autonomous Regions where frequency values of 330 and 350 times/year for milk were recorded.

Table 5. Univariate correlation coefficients between plasma retinol, plasma $\beta$-carotene and selected biochemical indicators and dietary factors in subjects from sixty-five rural Chinese counties

\begin{tabular}{|c|c|c|c|c|}
\hline & \multicolumn{2}{|c|}{ Plasma retinol } & \multicolumn{2}{|c|}{ Plasma $\beta$-carotene } \\
\hline & Males & Females & Males & Females \\
\hline \multicolumn{5}{|l|}{ Plasma indicators } \\
\hline Retinol $(\mu \mathrm{mol} / \mathrm{l})$ & - & - & $0.27^{*}$ & $0.34^{* *}$ \\
\hline$\beta$-Carotene $(\mu \mathrm{mol} / \mathrm{l})$ & $0 \cdot 27^{*}$ & $0.34^{* *}$ & - & - \\
\hline Retinol-binding protein $(\mu \mathrm{mol} / 1)$ & $0.39 * *$ & $0.33^{* *}$ & 0.06 & 0.21 \\
\hline$\alpha$-Tocopherol $(\mu \mathrm{mol} / \mathrm{l})$ & $0.27^{*}$ & $0 \cdot 38^{* *}$ & $0 \cdot 11$ & 0.04 \\
\hline Vitamin $\mathrm{C}(\mu \mathrm{mol} / \mathrm{l})$ & $0-09$ & $0 \cdot 10$ & $0 \cdot 32 * *$ & $0.32 * *$ \\
\hline Total cholesterol $(\mu \mathrm{mol} / \mathrm{l})$ & $0 \cdot 34^{* *}$ & $0.35^{* *}$ & 0.23 & 0.20 \\
\hline Non-HDL cholesterol $(\mu \mathrm{mol} / \mathrm{l})$ & $0 \cdot 28^{*}$ & $0.28^{*}$ & 0.21 & $0 \cdot 20$ \\
\hline Apolipoprotein B ( $\mu \mathrm{mol} / \mathrm{l})$ & $0-32^{* * *}$ & $0.26^{*}$ & $0.30^{*}$ & $0 \cdot 18$ \\
\hline Apolipoprotein A1 ( $\mu \mathrm{mol} / 1)$ & $0-28 *$ & 0.22 & 0.22 & $0 \cdot 12$ \\
\hline Testosterone, males $(\mu \mathrm{mol} / \mathrm{l})$ & $0 \cdot 34^{*}$ & - & 0.24 & - \\
\hline \multicolumn{5}{|l|}{ Dietary intakes } \\
\hline Green vegetables (times/year) & $0-03$ & -0.06 & $0.26^{*}$ & $0 \cdot 29 *$ \\
\hline Sweet potatoes (times/year) & $0 \cdot 16$ & $0 \cdot 15$ & 0.04 & $0 \cdot 25^{*}$ \\
\hline Meat (times/year) & $0.53^{* * *}$ & 0.20 & 0.22 & $0 \cdot 11$ \\
\hline Alcohol (times/year) & $0.54 * * *$ & 0.15 & 0.13 & -0.07 \\
\hline Oil intake $(\mathrm{g} / \mathrm{d}) \dagger$ & $0.39 * *$ & 0.16 & 0.21 & 0.15 \\
\hline Cellulose $(\mathrm{g} / \mathrm{d})_{\ddagger}^{ \pm}$ & $-0.49^{* * *}$ & -0.15 & -0.07 & -0.05 \\
\hline Total neutral-detergent fibre $(\mathrm{g} / \mathrm{d}) \ddagger$ & $-0 \cdot 37^{* *}$ & -0.04 & -0.13 & $-0 \cdot 11$ \\
\hline Plant protein $(\mathrm{g} / \mathrm{d}) \ddagger$ & $-0.59 * * *$ & $-0 \cdot 26^{*}$ & $-0 \cdot 36^{* *}$ & $-0 \cdot 41^{* *}$ \\
\hline
\end{tabular}

* $P<0.05, * * P<0.01, * * * P<0.001$.

$\dagger$ Peanut, sesame, cottonseed and soyabean oils, as measured in a $3 \mathrm{~d}$ household dietary survey.

‡ Estimated intake from food-composition analysis. 


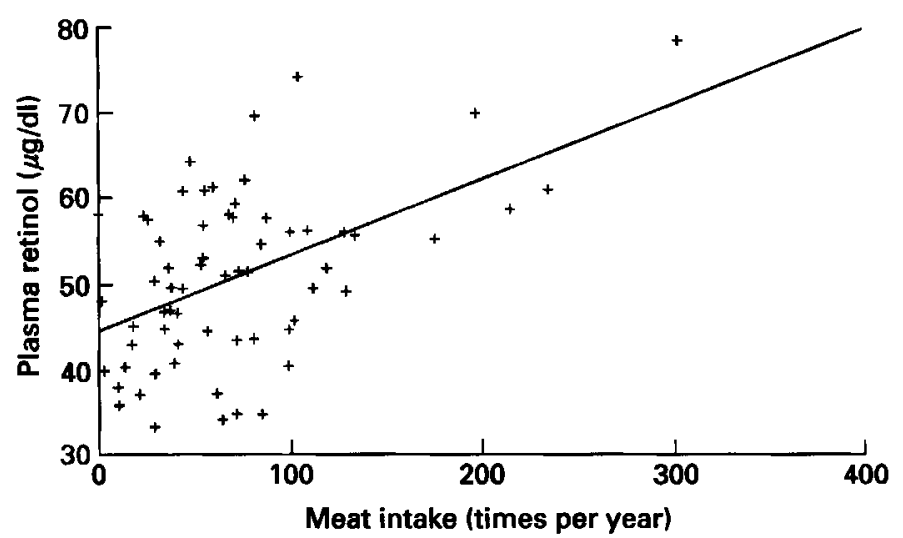

Fig. 1. Relationship between plasma retinol concentration and meat intake for male subjects in sixty-five rural Chinese counties $(r 0.53, P<0.001)$.

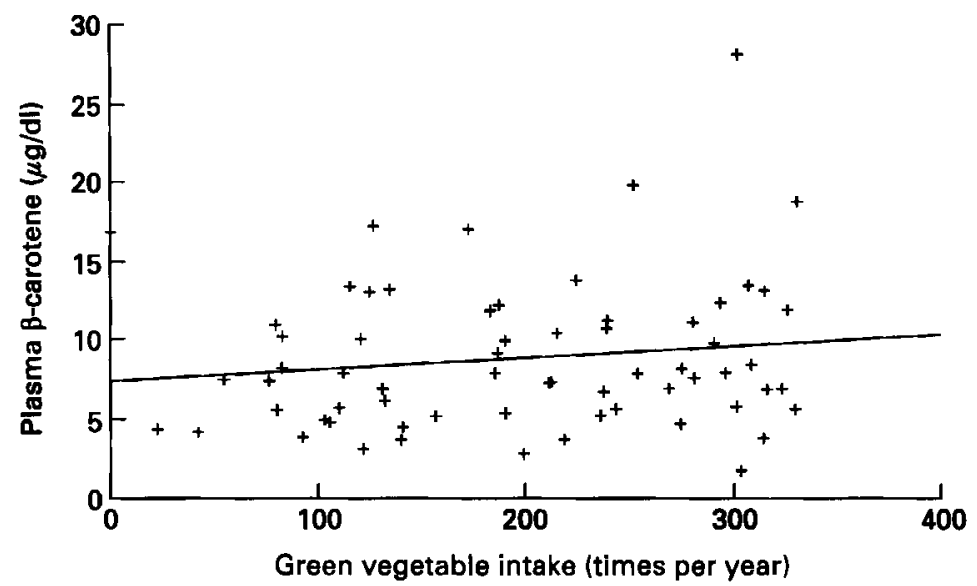

Fig. 2. Relationship between plasma $\beta$-carotene concentration and green vegetable intake for male subjects in sixty-five rural Chinese counties $(r 0.26, P<0.05)$.

\section{DISCUSSION}

County means for plasma retinol in China were within the range considered to be normal for Western subjects. However, these two ranges are not fully comparable because the Chinese range represents county means whereas the Western range is for individual subjects. Thus, where the county mean was close to or below the minimum value of the Western range, some individuals were likely to be below this minimum.

Mean plasma retinol values were below $1.05 \mu \mathrm{mol} / 1$ for eleven of the 260 pooled samples $(4.2 \%)$ surveyed. On the basis of the observed variance of the distribution of commune values and assuming a normal distribution, less than $2 \%$ of the population was estimated to have plasma retinol values below $0.7 \mu \mathrm{mol} / 1$ and approximately $5 \%$ below $1.05 \mu \mathrm{mol} / 1$. Except for Sonjiang county in Shanghai municipality, the 'deficient' counties were all located in inland areas. High mean plasma retinol values $(>2 \cdot 1 \mu \mathrm{mol} / 1)$ were observed in four counties which were either coastal or livestock producing. Plasma retinol values reflect vitamin A status only when liver stores are depleted (or excessively high). When liver vitamin A storage is between 0.07 and $1.0 \mu \mathrm{mol} / \mathrm{g}$ liver, plasma retinol is 
homeostatically controlled (Gibson, 1990), seldom falling below 1.05 $\mu \mathrm{mol} / 1$. At plasma levels below $0.7 \mu \mathrm{mol} / 1$, some individuals may exhibit functional impairment, including poor dark adaptation, night blindness, ocular lesions and possibly impaired immune function (Pilch, 1985; Gibson, 1990).

More striking were the low plasma levels of $\alpha$ - and $\beta$-carotene, considering the vegetablebased Chinese diet, with the mean of all sixty-five counties being close to the lower end of the Western range. None of the sixty-five counties had mean plasma $\beta$-carotene values higher than $0.5 \mu \mathrm{mol} / 1$ which is considered average by Western standards (Ascherio et al. 1992). More than half (57\%) of the 130 groups of men and women (approximately fifty individuals per group) had mean plasma $\beta$-carotene levels lower than $0 \cdot 19 \mu \mathrm{mol} / 1$ and many $(12 \%)$ were lower than $0.09 \mu \mathrm{mol} / 1$. $\alpha$-Carotene values were similarly low. In countries such as China where carotenoids provide the major sources of vitamin $A$, serum carotenoids may serve as a useful secondary index of vitamin A status (Le Francois et al. 1981), although it should be noted that plasma or serum carotenoids mostly reflect current intakes of carotenoids (Olson, 1984). About fifty carotenoids show provitamin A activity and it is not certain whether $\beta$-carotene is the major source of provitamin $A$ in all survey counties. Large amounts of other carotenoids such as cryptoxanthin in the diet, for example, possibly could account for low plasma $\beta$-carotene but normal retinol levels in this population.

Plasma retinol and plasma $\beta$-carotene were significantly correlated with each other $(r$ $0.33, P<0.01$ ). This would indicate either that diets containing more animal products also contained more carotenoid-rich fruits and vegetables or that plasma retinol levels depended to a large extent on conversion from $\beta$-carotene. The survey data reported here support the latter interpretation. There has been some controversy concerning the normal relationships between these variables. According to Olson (1981), 'in healthy subjects plasma carotenoids and vitamin A values are not correlated', however, studies in West Africa showed that plasma retinol and plasma carotenoids were correlated in populations, especially children of less industrialized countries (Le Francois et al. 1981). The present study shows this to be the case also in China. Olson (1981) suggested that this was a special case that occurred only 'in areas where malnutrition is common, where dietary carotenoids are essentially the only source of this nutrient, and where the composition of the diet remains relatively constant throughout the year, carotenoids might well serve as a useful secondary indicator of a potential problem with vitamin A malnutrition'. The term 'special case' may not be appropriate considering the percentage of the world's population in which this correlation is found. Also the use of the term 'malnutrition' could be questioned in view of the extent of diet-related chronic diseases in those parts of the world where the consumption of animal products, and therefore vitamin $\mathbf{A}$, is high. In reference to Chinese adults, the phrase 'in areas where there is less overnutrition' would be more appropriate than 'in areas where malnutrition is common'.

The factors that determine plasma carotenoid levels are not fully known but are likely to include dietary intake, intestinal destruction, efficiency of absorption and metabolism, and rate of tissue uptake (Parker, 1989). Smoking may also affect carotenoid levels (Stryker et al. 1988). The dietary supply of $\beta$-carotene or the total vitamin A equivalents in Chinese and US diets is difficult to compare because many foods are not fully analysed, and food consumption data are not expressed in the same manner. However, it has been estimated that over $40 \%$ and up to $75 \%$ of the retinol equivalents in the US diet are of animal origin whereas less than $10 \%$ of the retinol equivalents of the Chinese diet are from animal foods (Martson \& Raper, 1986; Olson, 1987).

Plasma $\beta$-carotene showed no correlation with intakes of total carotenoids, green vegetables, or fruit measured in the cross-sectional household dietary survey. However, 
there was a significant correlation of plasma $\beta$-carotene with the frequency of green vegetable consumption ( $r 0.26, P<0.05$ for males) as shown in Fig. 2, which may be a longer term indicator of intake of this food than dietary survey data. In fact, plasma $\alpha$ carotene but not plasma $\beta$-carotene showed a positive correlation with intakes of total carotenoids $(r 0.36 v . r 0.06)$, green vegetables $(r 0.47 v . r 0.13)$ and fruit $(r 0.25 v . r 0.06)$ for data for both sexes combined. This may reflect a more active conversion of dietary $\beta$ carotene to retinol. It is unlikely that season was a confounder in the analysis as blood samples were taken mostly in September and October, starting first in the north and working south. During this season vitamin A sources, i.e. fresh green vegetables, are still widely available and so regional differences cannot be attributed to seasonal variation. Further, there was a significant correlation of plasma $\beta$-carotene with both plasma ascorbate $(r 0.38, P<0.01)$ and urinary ascorbate excretion $(r 0.31, P<0.05)$ for data for both sexes combined.

The sex differences in plasma levels of retinol and $\beta$-carotene (retinol and RBP significantly higher in males and $\beta$-carotene significantly higher in females) could be due to differences in the type and amount of foods being consumed and/or the extent of smoking by each sex. Dietary intakes were obtained by weighing food consumption for the entire household and therefore quantitative differences between the sexes were not available. However, data on the frequency of intake showed that men consumed fish, eggs and meat considerably more frequently than women but vegetables and fruit no more frequently (Table 4). As smoking can influence both food intake and plasma carotene levels (Stryker et al. 1988), this could be a factor in the differences between the sexes, as reported daily cigarette consumption and plasma cotinine levels were both higher in men. The mean daily number of manufactured cigarettes consumed by men was 6.9 (SD 4.3) and by women 0.5 (SD 0.9), and the respective mean plasma cotinine levels were 0.85 (SD 0.30) and 0.11 (SD 0.17) $\mu \mathrm{mol} / 1$ (Chen et al. 1990). In addition to manufactured cigarettes, an equivalent amount of other tobacco is also consumed in China, mostly in the form of homemade cigarettes, pipe, water pipe, and snuff. However, for males, although there was no significant correlation between plasma $\beta$-carotene and total tobacco consumption, the correlation with plasma cotinine levels was positive $(r 0.25, P<0.05)$. This indicates that at the national level smoking may not be a plausible explanation of sex differences in plasma carotene levels.

Sex differences in serum levels of retinol and $\beta$-carotene have also been observed in the US (Williams et al. 1951; Leitner et al. 1960; Gravesen, 1967; Kasper, 1969; Vuilleumier et al. 1983; Friedman et al. 1986; Comstock et al. 1988). Metabolic factors, also, might account for these sex differences. It has been suggested by several investigators (Williams et al. 1951; Leitner et al. 1960; Gravesen, 1967; Kasper, 1969; Vuilleumier et al. 1983; Friedman et al. 1986; Comstock et al. 1988) that men have higher requirements for retinol than women. If the level of $\beta$-carotene in the blood represents surplus to what has been used for retinol synthesis in the gut mucosa, then the sex difference could be explained by a higher rate of conversion of $\beta$-carotene to retinol in men, rather than differences in vegetable consumption (Thurnham et al. 1988). This hypothesis is supported by the lack of a difference between the sexes for the non-provitamin A carotenoids in plasma and in frequency of vegetable consumption in the present study.

Supported in part by NIH grant 5RO1CA33638, the Chinese Academy of Preventive Medicine, the UK Imperial Cancer Research Fund, the US Food and Drug Administration, the American Institute for Cancer Research, and several American industry groups. 


\section{REFERENCES}

Ascherio, A., Stampfer, M., Colditz, G., Rimm, E., Litin, L. \& Willett, W. (1992). Correlations of vitamin A and $E$ intakes with the plasma concentrations of carotenoids and tocopherols among American men and women. Journal of Nutrition 122, 1792-1801.

Campbell, T., Brun, T., Chen, J., Feng, Z. \& Parpia, B. (1990). Questioning riboflavin recommendations on the basis of a survey in China. American Journal of Clinical Nutrition 51, 436-445.

Chen, C. (1986). The National Nutrition Survey of China, 1982: summary results. Food and Nutrition 1986 12, 58-60.

Chen, J., Campbell, T., Li, J. \& Peto, R. (1990). Diet, Lifestyle and Mortality in the People's Republic of China: A Study of the Characteristics of 65 Chinese Counties. Oxford, Ithaca and Beijing: Joint Publication of Oxford University Press, Cornell University Press and the People's Medical Publishing House.

Comstock, G., Menkes, M., Schober, S., Vuilleumier, J.-P., \& Helsing, K. (1988). Serum levels of retinol, $\beta$ carotene, and $\alpha$-tocopherol in older adults. American Journal of Epidemiology 127, 114-123.

Cui, Y. (1987). Public Health in the People's Republic of China. Wanchai, Hong Kong and Beijing, China: Joint publication of the People's Medical Publishing House and China and Medical China Publishing Ltd.

Department of Health and Human Services (1983). Dietary intake source data: United States 1976-1980. Series II, no. 231. Hyatsville, MD: Pub no. PHS 83-1681 National Health Survey.

DeRuyter, M. \& Deleenheer, A. (1978). Simultaneous determination of retinol and retinyl esters in serum or plasma by reversed-phase high performance liquid chromatography. Clinical Chemistry 24, 1920-1923.

Driskell, W., Neese, J., Bryand, C. \& Bashor, M. (1982). Measurement of vitamin A and vitamin E in human serum by high-performance liquid chromatography. Journal of Chromatography 231, 439-444.

Ershow, A. \& Wong-Chen, K. (1990). Chinese food composition tables. Journal of Food Composition and Analysis 3, $191-437$.

Farthing, J., Mata, L., Urrutia, J. J. \& Kronmal, R. (1986). Natural history of giardia infection in infants and children in rural Guatemala and its impact on physical growth. American Journal of Clinical Nutrition 43, 395-405.

Freedman, R. (1978). Review of recently published work dealing with nutrition research in mainland China. World Review of Nutrition and Dietetics 30, 1-22.

Friedman, G., Blaner, W., Goodman, D., Vogelman, J., Brind, J., Hoover, R., Fireman, B. \& Orentreich, R. (1986). Serum retinol and retinol-binding levels do not predict subsequent lung cancer. American Journal of Epidemiology 123, 781-789.

Gibson, R. (1990). Principles of Nutritional Assessment. Oxford: Oxford University Press.

Gopalan, C., Vankatachalam, P. \& Bhavani, B. (1960). Studies of vitamin A deficiency in children. American Journal of Clinical Nutrition 8, 833-840.

Gravesen, K. (1967). Vitamin A and carotene in serum from healthy Danish subjects. Scandinavian Journal of Clinical and Laboratory Investigation 20, 57-62.

Institute of Health (1980). Chinese Food Composition Table. Beijing, People's Republic of China: China Medical Publishing House.

Kanai, M., Raz, A. \& Goodman, D. (1968). Retinol-binding protein: the transport protein for vitamin A in human plasma. Journal of Clinical Investigation 47, $2025-2044$.

Kasper, H. (1969). Die vitamin-A und cartonkonzentration im serum. I. Bei optimal ernahrten personen in Westdeutschland (Vitamin A and carotene concentration in serum: among optimally nourished people in West Germany). Internationale Zeitschrift für Vitaminforschung 38, 142-148.

Katsampes, C., McCoord, A. \& Phillips, W. (1944). Vitamin A absorption test in cases of giardiasis. American Journal of Diseases of Children 67, 189-193.

Latham, M. \& Solon, F. (1986). Vitamin A deficiency control in the Philippines. In Vitamin A Deficiency and Its Control [J. C. Bauernfeind, editor]. Orlando FL: Academic Press, Inc.

Le Francois, P., Chevassus-Agnes, S. \& Ndiaye, A. (1981). Plasma carotenoids as a useful indicator of vitamin A status. American Journal of Clinical Nutrition 34, 434.

Lie, C., Ying, C., En-Lin, W., Brun, T. \& Geissler, C. (1993). Impact of large dose vitamin A supplementation on childhood diarrhoea, respiratory disease and growth. European Journal of Clinical Nutrition 47, 88-96.

Leitner, Z., Moore, T. \& Sharman, I. (1960). Vitamin A and vitamin E in human blood. 1. Levels of vitamin A and carotenoids in British men and women. British Journal of Nutrition 14, 157-169.

Mancini, G., Carbonara, A. \& Heremans, J. (1965). Immunochemical quantitation of antigens by single radial immunodiffusion. Immunochemistry 2, 235-254.

Martson, R. \& Raper, N. (1986). Nutrient content of food supply. National Food Review 32, 9-12.

Olson, J. (1981). Reply to letter by Le Francois, Chevassus-Agnes and Ndiaye. American Journal of Clinical Nutrition 34, 435-436.

Olson, J. (1984). Serum levels of vitamin A and carotenoids as reflectors of nutritional status. Journal of the National Cancer Institute 73, 1439-1444.

Olson, J. A. (1987). Recommended dietary intakes (RDI) of vitamin A in humans. American Journal of Clinical Nutrition 45, 704-716.

Parker, R. (1989). Carotenoids in human blood and tissues. Journal of Nutrition 119, 101-104. 
Pilch, S. (1985). Assessment of the Vitamin A Status of the US Population Based on Data Collected in the Health and Nutritional Examination Surveys. Bethesda, MD: Life Science Research Office, Federation of American Societies for Experimental Biology.

Solomons, N. \& Russell, R. (1980). The interaction of vitamin A and zinc: implications for human nutrition. American Journal of Clinical Nutrition 33, 2031-2040.

Solon, F., Popkin, B., Fernandez, T. \& Latham, M. (1978). Vitamin A deficiency in the Philippines: a study of xerophthalmia in Cebu. American Journal of Clinical Nutrition 31, 360-368.

Stacewicz-Sapuntzakis, M., Bowen, P. E., Kikendall, J. W. \& Burgess, M. (1987). Simultaneous determination of serum retinol and various carotenoids; their distribution in middle-aged men and women. Journal of Micronutrient Analysis 3, 27-45.

Statistical Analysis Systems (1985). SAS User's Guide: Basics Version 5. Cary, NC: SAS Institute, Inc.

Stryker, W. S., Kaplan, L. A., Stein, E. A., Stampfer, M. J., Sober, A. \& Willett, W. C. (1988). The relation of diet, cigarette smoking, and alcohol consumption to plasma $\beta$-carotene and $\alpha$-tocopherol levels. American Journal of Epidemiology 127, 283-296.

Thurnham, D., Munoz, N., Lu, J., Wahrendorf, J., Zheng, S.-F., Hambidge, K. \& Crespi, M., (1988). Nutritional and haematological status of Chinese farmers: the influence of 13.5 months treatment with riboflavin, retinol and zinc. European Journal of Clinical Nutrition 42, 647-660.

Thurnham, D., Rathakette, P., Hambidge, K., Munoz, N. \& Crespi, M. (1982). Riboflavin, vitamin A and zinc status in Chinese subjects in a high-risk area for oesophageal cancer in China. Human Nutrition: Clinical Nutrition 36C, 337-349.

Tian, Q., Yang, B., Wang, S., Huang, H., Li, Y. \& Lu, Z. (1988). An assay on serum vitamin A level of 774 children in the countryside. Acta Nutrimenta Sinica 10, 192-195.

Tietz, N. W. (1986). Textbood of Clinical Chemistry. Philadelphia, PA: W. B. Saunders Co.

Underwood, B. (1984). Vitamin A in human and animal nutrition. In The Retinoids [M. Sporn, A. Roberts and D. Goodman, editors]. Orlando, FL: Academic Press.

United States Department of Agriculture, Human Nutrition Information Service, Consumer Nutrition Division (1984). Nutrient Intakes: Individuals in 48 States, Year 1977-78. NFCS 1977-78 Report no. 1-2. Hyattsville, MD: USDA.

United States Department of Agriculture, Human Nutrition Information Service, Nutrition Monitoring Division (1986). Nationwide Food Consumption Survey Continuing Survey of Food Intakes by Individuals: Men 19-50 Years, I Day. Report 85-3. Hyattsville, MD: USDA.

Vuilleumier, J.-P., Keller, H., Gysel, D. \& Hunziker, F. (1983). Clinical methods for the routine assessment of the vitamin status in human populations. International Journal for Vitamin and Nutrition Research 53, $265-272$.

Wang, E., Zhu, Q., Huang, L., Liang, X., Tian, L., Han, L. \& Zhang, W. (1989a). Investigation of serum vitamin A level in children under 3 years old in both city and countryside of Wuhan. Acta Nutrimenta Sinica 1, 86-88.

Wang, G., Root, M., Chen, J., Ye, X. \& Campbell, T. (1989b). Routine assay of plasma carotenes by HPLC with an internal standard. Journal of Micronutrient Analysis 5, 3-14.

Williams, H., Parker, J., Pierce, Z., Hart, J., Fiala, G. \& Pilcher, H. L. (1951). Nutritional Status Survey. Groton Township, New York. Journal of the American Dietetic Association 27, 215-221.

Yang, C., Sun, Y., Yang, Q., Miller, K., Li, G., Zheng, S.-F., Ershow, A., Blot, W. \& Li, J. (1984). Vitamin A and other deficiencies in Linxian, a high esophageal cancer incidence area in Northern China. Journal of the National Cancer Institute 73, 1449-1453.

Zhao, X.-H. (1988). Vitamin A nutritional status of Chinese population. Journal of Nutritional Science and Vitaminology, Special Suppl., 202-205. 